\title{
Clinical Profile of COVID-19 Patients in Bangladesh: Study in a Tertiary Care Hospital, Cumilla, Bangladesh \\ Hoq AJMS $^{1 *}$, Dr. Fahmida Sultana ${ }^{2}$, Babar ZUM ${ }^{3}$
}

${ }^{1,3}$ Assistant Professor, Dept. of Dermatology and Venereology, Cumilla Medical College Hospital, Cumilla, Bangladesh

${ }^{2}$ Medical Officer, SK Rasel National Gastroliver Institute and Hospital, Mohakhali, Dhaka, Bangladesh

DOI: $10.36347 /$ sjams.2020.v08i11.004

| Received: 13.11.2020 | Accepted: 24.11.2020 | Published: 07.12.2020

*Corresponding author: Dr. Abu Jafar Md. Shahidul Hoq

Abstract

Original Research Article

Introduction: Severe acute respiratory syndrome coronavirus 2 (SARS-CoV-2) is the strain of coronavirus that causes coronavirus disease 2019 (COVID-19). Objective: The aim of the study was to evaluate the clinical profile of covid19 patients in Bangladesh. Method: This cross-sectional observational study was done in Cumilla Medical College Hospital, Cumilla, Bangladesh (Covid-19 dedicated hospital) during the period from April 2020 to June 2020 . Total 20 hospitalized patients, with laboratory confirmed COVID-19 were included in the study. We obtained the medical records and compiled data of patients admitted in the isolation wards of hospital. Results: during the study, maximum $(50.0 \%)$ patients were in the age group of $41-50$ years. $42 \%$ had cardiovascular diseases, $20 \%$ had hypertension, $3 \%$ had hypothyroidism, 7\% had COPD. Most of the patients had fever, 50\% and cough, $60 \%$ followed by $40 \%$ had myalgia, 20\% had sputum production, $10 \%$ had headache, $45 \%$ had Diarrhoea, $15 \%$ had dyspnea. $80 \%$ had abnormal Chest X-ray at the time of admission, followed by $42 \%$ had thrombocytopenia, $30 \%$ had lymphopenia, $15 \%$ had Leukopenia. Conclusion: This study showed variable range of presentation. Male patients are at risk for Covid-19 infection. Thrombocytopenia, lymphopenia, Leukopenia. Lymphopenia do help in prognosis. Old age and comorbidity are associated with poor prognosis. For treatment guidelines and testing protocols further study is needed.

Keywords: Severe acute respiratory syndrome coronavirus 2 (SARS-CoV-2), COVID-19 pandemic, clinical Profile. Copyright $\odot 2020$ The Author(s): This is an open-access article distributed under the terms of the Creative Commons Attribution 4.0 International License (CC BY-NC 4.0) which permits unrestricted use, distribution, and reproduction in any medium for non-commercial use provided the original author and source are credited.

\section{INTRODUCTION}

Severe acute respiratory syndrome coronavirus 2 (SARS-CoV-2) is the strain of coronavirus that causes coronavirus disease 2019 (COVID-19), the respiratory illness responsible for the COVID-19 pandemic. Colloquially known as simply the coronavirus, it was previously referred to by its provisional name, 2019 novel coronavirus (2019-nCoV), and has also been called human coronavirus 2019 (HCoV-19 or hCoV19) [1-4].

The 2019-nCoV has close similarity to bat coronaviruses, and it has been postulated that bats are the primary source. While the origin of the 2019-nCoV is still being investigated, current evidence suggests spread to humans occurred via transmission from wild animals illegally sold in the Huanan Seafood Wholesale Market [5]. It spread rapidly through China infecting more than 85,000 people. Within a few months it engulfed the Europe causing massive loss of life and property in Italy, Spain, France, Germany, UK and then USA. It is now set to gain a foothold in India which is the second most populous country of the world. As of now more than 650,000 people have been infected and 28,000 people have succumbed to the illness across the globe. The World Health Organization declared the outbreak a Public Health Emergency of International Concern on 30 January 2020, and a pandemic on 11 March 2020[6, 7].

The virus was confirmed to have spread to Bangladesh in March 2020. The first three known cases were reported on 8 March 2020 by the country's epidemiology institute, IEDCR. Since then, the pandemic has spread day by day over the whole nation and the number of affected people has been increasing. As of 21 July 2020, there have been a total of 210,525 confirmed cases in the country, with 114,870 recoveries and 2,709 deaths [8]. Illness ranges in severity from asymptomatic or mild to severe; a significant proportion of patients with clinically evident infection develop severe disease [9]. In this study our main goal is to evaluate the clinical Profile of Covid-19 Patients in Bangladesh. 


\section{OBJECTIVE}

\section{General objective}

- To assess the clinical Profile of Covid-19 Patients in Bangladesh.

\section{Specific objective}

- To detect sign and symptoms of the patients.

- To identify laboratory findings of the patients.

\section{Methodology}

A cross-sectional observatory study was done in in Cumilla Medical College Hospital, Cumilla, Bangladesh (Covid-19 dedicated hospital) during the period from April 2020 to June 2020. We obtained the medical records and compiled data of patients admitted in the isolation wards of hospital. All data was received through complete consent of patients and hospital. We assessed complete blood count, blood chemical analysis, coagulation testing, liver and renal function tests, serum electrolytes, lactate dehydrogenase, and creatine kinase. Fever was defined as an axillary temperature of $37.5^{\circ} \mathrm{C}$ or higher. Lymphocytopenia and lymphocytosis were defined as a lymphocyte count of less than 1500 cells and more than 4000 cells per cubic millimeter, respectively. Collected data was collated and appropriate statistical analysis was done using computer-based SPSS (Statistical program for scientific study) package

\section{RESULTS}

In table 1 shows age distribution of the patients. Maximum $(50.0 \%)$ patients were in the age group of $41-50$ years. The following table is given below in detail:

Table-1: Distribution of patients according to age $(\mathbf{n}=\mathbf{2 0})$

\begin{tabular}{|l|c|}
\hline Age (years) & $\mathbf{( \% )}$ \\
\hline $21-30$ & 13.9 \\
\hline $31-40$ & 36.1 \\
\hline $41-50$ & 50.0 \\
\hline
\end{tabular}

In figure-1 shows gender distribution of the patients where $92 \%$ patients were male, $8 \%$ were female. The following figure is given below in detail:

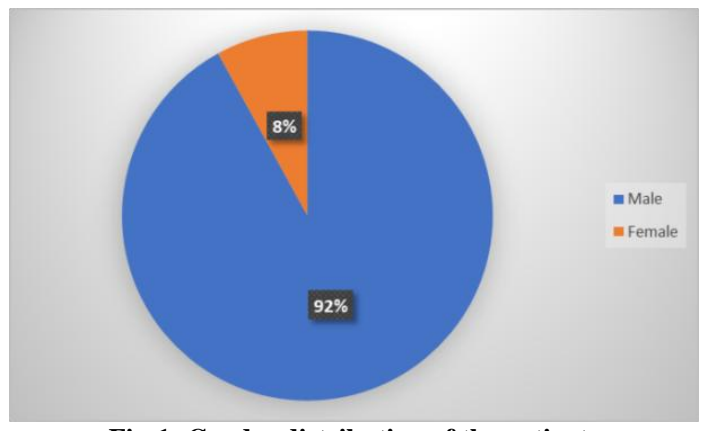

Fig-1: Gender distribution of the patients
In table-2 shows co morbidity of the patients where $42 \%$ had cardiovascular diseases, $20 \%$ had hypertension, $3 \%$ had hypothyroidism, $7 \%$ had COPD. The following table is given below in detail:

Table-2: co-morbidity of the patients

\begin{tabular}{|l|c|}
\hline Co morbidity & \% \\
\hline Diabetes & $28 \%$ \\
\hline Hypertension & $20 \%$ \\
\hline Cardiovascular Disease & $42 \%$ \\
\hline COPD & $7 \%$ \\
\hline Hypothyroidism & $3 \%$ \\
\hline
\end{tabular}

In table-3 shows sign and symptoms of the patients where most of the patients had fever, $50 \%$ and cough, $60 \%$ followed by $40 \%$ had myalgia, $20 \%$ had sputum production, $10 \%$ had headache, $45 \%$ had Diarrhoea, $15 \%$ had dyspnea. The following table is given below in detail:

Table-3: Sign and symptoms of the patients

\begin{tabular}{|l|c|}
\hline Sign and symptoms & \% \\
\hline Fever & $50 \%$ \\
\hline Cough & $60 \%$ \\
\hline Myalgia & $40 \%$ \\
\hline Sputum production & $20 \%$ \\
\hline Headache & $10 \%$ \\
\hline Diarrhoea & $45 \%$ \\
\hline Dyspnea & $15 \%$ \\
\hline Maculopapular rash & $10 \%$ \\
\hline
\end{tabular}

In table-4 shows distribution of the patients according to laboratory findings where $80 \%$ had abnormal Chest X-ray at the time of admission, followed by $42 \%$ had thrombocytopenia, $30 \%$ had lymphopenia, $15 \%$ had Leukopenia. The following table is given below in detail:

Table-4: Distribution of the patients according to laboratory findings

\begin{tabular}{|l|c|}
\hline Laboratory findings & \% \\
\hline Leukopenia & $15 \%$ \\
\hline lymphopenia & $30 \%$ \\
\hline leukocytosis & $5 \%$ \\
\hline Lymphocytosis & $10 \%$ \\
\hline Raised HCT & $12 \%$ \\
\hline Thrombocytopenia & $42 \%$ \\
\hline Abnormal ECG & $30 \%$ \\
\hline Abnormal Chest X-ray & $80 \%$ \\
\hline
\end{tabular}

In figure-2 shows distribution of the patients according to oxygen support where $10 \%$ needed oxygen support and $90 \%$ didn't need any oxygen support. The following figure is given below in detail: 


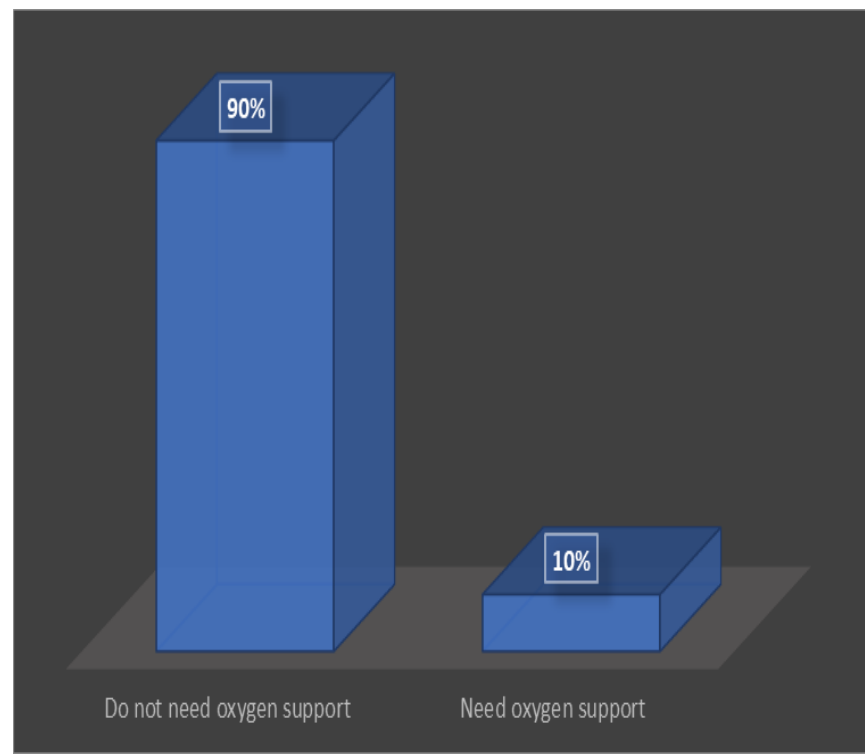

Fig-2: Distribution of the patients according to oxygen support

In figure-3 shows chest X-ray report of the patients where bilateral pneumonitis with LV type cardiomegaly had found. The following figure is given below in detail:

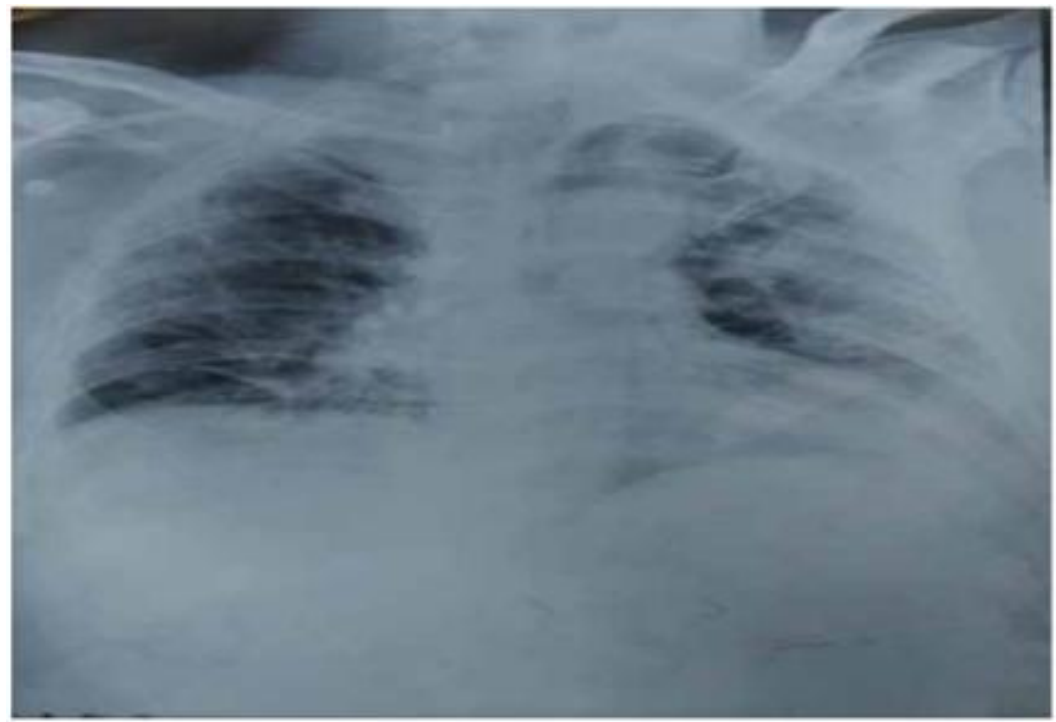

Fig-3: Chest X-ray report of the patients

\section{DiSCUSSION}

In our study we found that, $(50.0 \%)$ patients were in the age group of $41-50$ years. Which was supported by several studies $[5,11]$. The results indicate that with increasing age, the immune cells are more susceptible to damage by the virus, and hence their immunity maybe weakened [12].

Most of the patients having Covid-19 were male $(92 \%)$ which was similar to one study by which show $73.0 \%$ male predominance [5] but higher than that reported by another study (54.3\%)[11]. This male predominance may have happened due to increased foreign travel by males for occupational or educational purposes.
We also found that, most of the patients had fever, $50 \%$ and cough, $60 \%$ followed by $40 \%$ had myalgia, $20 \%$ had sputum production, $10 \%$ had headache, $45 \%$ had Diarrhoea, $15 \%$ had dyspnea and Maculopapular rash had $10 \%$. Which is supported by one study where cough was the most common symptom present in patients $(85.71 \%)$ followed by fever (78.57\%) 10which was in contrast to that reported in one study where fever was the most common symptom found $(91.7 \%)[13]$.

Another report found that, 11 patients $(52.38 \%)$ presented with lymphopenia. Some patients also presented with lymphopenia with thrombocytopenia (14.28\%). Lymhopenia was much more commonly seen in male patients $(64.28 \%)$ as compared to females $(28.57 \%)$. All patients requiring 
oxygen support, presented with lymphopenia indicating, that occurrence of lymphopenia can be used as a marker of prognosis [10]. Where as in our study distribution of the patients according to laboratory findings, $80 \%$ had abnormal Chest X-ray at the time of admission, followed by $42 \%$ had thrombocytopenia, $30 \%$ had lymphopenia, $15 \%$ had Leukopenia.

We also found that, according to oxygen support where $10 \%$ needed oxygen support and $90 \%$ didn't need any oxygen support. Which similar to several studies $[10,14]$.

\section{Conclusion}

This study showed variable range of presentation. Male patients are at risk for Covid-19 infection. Thrombocytopenia, lymphopenia, Leukopenia. Lymphopenia do help in prognosis. Old age and comorbidity are associated with poor prognosis. For treatment guidelines and testing protocols further study is needed.

\section{REFERENCE}

1. Gorbalenya AE, Baker SC, Baric R, Groot RJ, Drosten C, Gulyaeva AA, Haagmans BL, Lauber C, Leontovich AM, Neuman BW, Penzar D. Severe acute respiratory syndrome-related coronavirus: The species and its viruses-a statement of the Coronavirus Study Group.

2. "Coronavirus disease named Covid-19". BBC News Online. 11 February 2020. Archived from the original on 15 February 2020. Retrieved 15 February 2020.

3. Surveillance case definitions for human infection with novel coronavirus ( $\mathrm{nCoV})$ : interim guidance v1, January 2020 (Report). World Health Organization. January 2020. hdl:10665/330376. WHO/2019-nCoV/Surveillance/v2020.1.

4. Healthcare Professionals: Frequently Asked Questions and Answers". United States Centers for Disease Control and Prevention (CDC). 11 February 2020. Archived from the original on 14 February 2020. Retrieved 15 February 2020.

5. Chen N, Zhou M, Dong X, Qu J, Gong F, Han Y, Qiu Y, Wang J, Liu Y, Wei Y, Yu T. Epidemiological and clinical characteristics of 99 cases of 2019 novel coronavirus pneumonia in Wuhan, China: a descriptive study. The Lancet. 2020 Feb 15;395(10223):507-13.

6. Guan WJ, Ni ZY, Hu Y, Liang WH, Ou CQ, He JX, Liu L, Shan H, Lei CL, Hui DS, Du B. Clinical characteristics of coronavirus disease 2019 in China. New England journal of medicine. 2020 Apr 30;382(18):1708-20.

7. Lei H, Li Y, Xiao S, Lin CH, Norris SL, Wei D, Hu $\mathrm{Z}$, Ji S. Routes of transmission of influenza A H1N1, SARS CoV, and norovirus in air cabin: comparative analyses. Indoor Air. 2018 May;28(3):394-403.

8. Research (IEDCR), Institute of Epidemiology, Disease Control and Research, corona.gov.bd (in Bengali). Retrieved 3 May 2020.

9. Zhu N, Zhang D, Wang W, Li X, Yang B, Song J, Zhao X, Huang B, Shi W, Lu R, Niu P. A novel coronavirus from patients with pneumonia in China, 2019. New England Journal of Medicine. 2020 Jan 24.

10. Bhandari S, Bhargava A, Sharma S, Keshwani P, Sharma R, Banerjee S. Clinical profile of covid-19 infected patients admitted in a tertiary care hospital in north India. J Assoc Physicians India. 2020 May;68:13-7.

11. Zhu N, Zhang D, Wang W. China Novel Coronavirus Investigating and Research Team. A novel coronavirus from patients with pneumonia in China, 2019 [published January 24, 2020]. N Engl J Med.

12. Liu WJ, Zhao M, Liu K, Xu K, Wong G, Tan W, Gao GF. T-cell immunity of SARS-CoV: implications for vaccine development against MERS-CoV. Antiviral Res. 2017; 137:82-92.

13. Huang C, Wang Y, Li X, Ren L, Zhao J, Hu Y, Zhang L, Fan G, Xu J, Gu X, Cheng Z. Clinical features of patients infected with 2019 novel coronavirus in Wuhan, China. The lancet. $2020 \mathrm{Feb}$ 15;395(10223):497-506.

14. Saluja M, Pillai D, Jeliya S, Bauddh N, Chandel R. COVID 19-Clinical Profile, Radiological Presentation, Prognostic Predictors, Complications and Outcome: A Perspective from the Indian Subcontinent. J Assoc Physicians India. $2020 \mathrm{Jul}$ $1 ; 68: 13-8$. 